\title{
El contexto de recepción de Grocio a mediados del siglo XVII en la Monarquía Hispana*
}

\author{
JULIÁN VIEJO YHARRASSARRY **
}

\begin{abstract}
RESUMEN ABSTRACT
En el presente articulo pretendemos llamar la atención sobre la particular visión del mundo que dominaba en el interior de la Monarquía Católica. Una cosmovisión que fundada en la ausencia de política y la presencia de religión imponía las condiciones para una peculiar recepción de autores como Grocio que se debatían entre su más inicial rechazo como "hereje" y la aceptación y uso de alguna de sus obras en el entendimiento final de que acabó por convertirse al catolicismo.

In this papaer I suggest an interpretation about the peculiar world view inside the Catholic Monarchy. Based on the absence of politics and the presence of religion, the catholic world view imposed the conditions under wich authors like. Grotius were received in the Spanish Monarchy. Those conditions veried between the more radical rejection as "heretic", and the acceptance of some of his works from the understanding that Grotius was finally converted to Catholicism.
\end{abstract}

1. En 1629 Juan de Solórzano y Pereyra publicaba su obra Disputationem de Indiarum lure '. Grocio y su Mare Liberum tenían evidentemente un lugar en la obra aunque nuestro autor de Delft no aparecía directamente nom-

* Este trabajo forma parte del proyecto de investigación PB. 95-0181 dirigido por P. FERNÁNoEz Albaladejo.

* Universidad Autónoma de Madrid.

1 Disputationem de Indiarum lure sive de iusta Indiarum Occidentalium inquisitione, acquisitione, et retentione, tribus libris comprehensam, Madrid, 1629. Solórzano comenzó a escribir la obra quizá ya en 1618, pero será en 1626 cuando envie desde Lima el primer volumen y el 9 marzo de 1628 obtiene la licencia de impresión. Vid. el «Estudio preliminar» de OchOA Brun, M.A. a la edición de la Política Indiana de Solórzano de la "Biblioteca de Autores Hispanos». Madrid, 1972, págs. XIII-LXVI. 
brado y, por otra parte, Solórzano reconocía no haber podido aun leerla ${ }^{2}$. No obstante, el mismo Solórzano nos recordaba que el escrito ya había sido objeto de una minuciosa respuesta por parte de Serafín de Freitas ${ }^{3}$ y nos informaba, además, de la inclusión del opúsculo en el Index español de $1612^{4}$. Pero, y es esto lo que ahora más propiamente nos interesa, era ante todo la condición de «hereje» de Grocio lo que se trataba de evidenciar. El hijo de Solórzano, Gabriel Solórzano Paniagua, que llevó a cabo en 1639 la traducción al castellano de algunas partes del tomo segundo de las Disputationem, se encargaba por su parte de recordarnos esta «mácula» herética ${ }^{5}$. Y cuando el mismo Juan de Solórzano publicaba en 1648 una traducción-revisión de su obra latina repetía la operación, esta vez de una manera aun más significativa. En efecto, Maquiavelo y Bodino encontraban una plaza de honor entre aquellos herejes «...que se han atrevido a decir que antes en procurar y guardar la fe y ley christiana, ha enflaquecido y arruinado muchas republicas ${ }^{6} \%$. $Y$ de nuevo, Grocio compartía, ahora en esta compañía, la misma consideración ? Como se puede ya suponer, detrás de esta descalificación se escondía toda una concepción de la política que constituye precisamente el argumento del presente trabajo. Pero es aun necesario repasar otros testimonios. Quizá puedan depararnos algunas sorpresas.

Francisco Ramos del Manzano, en su Respuesta de España al Tratado de Francia ${ }^{8}$, que componía durante el año de 1667 contra las pretensiones

2 Disputationem... Liv. II, XIII, pp. 10 y ss. de la edición citada. Y también, Liv. II, Cap. I, págs. 48 et s. que cito: "Alacrior quoq; ad hâc pugnâ capessendam insurgo, quoniam audio etiam his ultimis annis librum quendâ sine Auctoris nomine pervulgatum esse, de his Indicanae dominationis iuribus plura tractantem, cui titulus est Mare Liberum, cuius copiam hucusque nancisci non potui..."

3 Freitas, S. de, De lusto Imperio Lusitanorum Asiatico. Valladolid, 1625 (Ed. Universidad de Valladolid, Valladolid, 1925).

4 Disputationem... Liv.II, Cap. I: «... \& huius nundinatio, \& relectio per sanctae Inquisitiones officium interdicta videtur, ut constat ex ultimo indice librorum prohibitorum ann. 1612 pág. $77 \%$. Vid. Index librorum prohibitorum et expurgatorum... Madrid, 1612. Grotius aparece como Hugo Grotius entre los autores Primae Classis (aquéllos cuyas obras están en principio prohibidas en su totalidad) en la pág. 54, y el Mare Liberum se inserta entre las obras Tertiae Classis (que agrupa obras prohibidas sin autor conocido), pág. 77, letra M: «Mare Liberum, sive, De lure, quod Batavus competit ad Indicana Comercio dissertatio".

5 Solórzano Paniagua, G., Traducción de la Dedicatoria Real y Epistolas Proemiales del Segundo Tomo del derecho, i govierno de las Indias Occidentales... por don Gabriel de Solorzano Paniagua y Trexo. Madrid, 1639.

6 Solórzano Pereira, J. Política Indiana, (Tomás y Valiente, F. y Barrero, A.M. Edts.), Madrid, 1996, Liv. I, Ch. VIII, 23, pág. 104.

7 Solorzano Pereira, J. Política..., Liv. X, Ch. X, 18, nota 29, pág. 129, (ed. Tomás y ValienTE-BARRERO).

8 Ramos del Manzano, F., Respuesta de España al Tratado de Francia sobre las pretensiones de la Reyna Christianissima. Madrid, 1667. Vid. nuestro trabajo, “El sueño de Nabuconosor. Religión y política en la Monarquía Católica a mediados del siglo XVIl'». Revista de Estudios Políticos (Nueva Época), abril-junio (1994), pág. 149, n. 19 para las dificultades de datación de la obra. 
posesivas de Luis XIV que dieron lugar a la denominada Guerra de Devolución, podía sin excesiva dificultad usar de ciertas proposiciones desarrolladas por Grocio en su De lure Belli ac Pacis. Se trataba de una utilización ciertamente instrumental que se orientaba a demostrar que las acciones emprendidas por el rey Cristianisimo no se acomodaban a las condiciones requeridas para una guerra justa, tal y como el autor suponía encontrarlas en la obra del jurista holandés. Por su parte, Pedro González de Salcedo, otro participante del lado del rey Católico en el mismo debate, no dudaba tampoco en realizar este género de utilización del De lure Belli ${ }^{9}$. Pero, Ramos del Manzano ya nos había advertido del hecho - lo que era probablemente una ficción inventada por él mismo ${ }^{10}$ - de que Grocio «muriò estimado, y Catolico en la Francia" ". Una "conversión" tanto más significativa, cuanto que el De lure Belli - lo que no era el caso para otras obras de Grocio- no será finalmente prohibido hasta el Index de $1732{ }^{12}$ y que, además, puede descu-

- Gonzalez de SAlCEdo, P. de, Examen de la verdad en respuesta a los tratados de los derechos de la Reyna Christianissima sobre varios estados de la Monarchia de España, s.l. s.a.

10 Vid. todavía sobre Ramos del Manzano, Martinez Ruiz, A., Francisco Ramos del Manzano, testigo de la crisis del siglo Xvil (1604-1683). Granada, 1980.

11 Ramos del Manzano, F., Respuesta... "A los que leyeren", in fine, (y nota 4 para la cita del De lure). Curiosamente un cierto rumor acerca de la conversión de Grocio se habia extendido con motivo de las posiciones teológicas adoptadas por nuestro autor acerca de las disputas dogmáticas entre protestantes y católicos ("Grotius papizans"), en otro contexto. Vid, ROELOFSEN, C.G., "Grotius and the International Politics of the Seventeenth Century", en BULL, H. KiNGSBURY, B. y Roberts, A. (Edts.), Hugo Grotius and International Relations, Oxford, 1992, pág. 130.

12 En el Novus librorum prohibitorum \& expurgatorum Index de 1632 el De lure aparecia en espera de ser expurgado (pág. 487 in fine: "Item eiusdem de lur. Belli ac pacis donec expurgentur"). En los Indices posteriores del siglo XVII no vuelve a aparecer. $Y$ vid. para el siglo XVIII, DEFOURNEAUX, M., Inquisición y censura de libros en la España del siglo XvII. Madrid, 1973, pág. 155. También, SCANDELLARI, S., " L'importanza di Pufendorf e dell'insegnamento del diritto naturale nei progetti di riforma degli studi giuridici nella Spagna de Cario Ill", in Fionillo, V. (Ed.), Samuel Putendort. Filosofo del Diritto e della Politica. Milán, 1996, págs. 225 et ss. He aqui la referencia en lo que se refiere al De lure delindex de 1632: en primer lugar Grocio se hallaba incluido aun entre los autores Primae Classis (en este index se reagruparon en la Primera Clase los autores cuyas obras estaban absolutamente prohibidas con aquellos susceptibles de ser expurgados). En la pág.486 se decia de él:

"Sive, Hugeianus Grotius, 1. C. Historicus, \& Poeta, misit etiam falcem in rem Theologicâ, Delphensis Batavus, eiusdem cum aliis Hollandiae, \& Roterodamensibus, ac Leydensibus sectae. Vivit adhuc". Tras otras obras se señala: "Eiusdem, Apologeticus, eourum, qui in Holandiae, Westfrisiaque nationibus praefuerunt \& c. Paris, 1622 ommino prohibenfur $=$ Sicut etiam Jjber de Satisfactione Christi, adversus Socinum $1617=$ Et liber inscriptus, Ordinum Hollandiae, pietas vindicata, 1613 \& Epicedia in obitum, Jacobo Arminii= et Mare Liberum, an. 1609 = et liber de iure belli \& pacis continens discursus politicus, Paris 1625= Vide etiam eius Poematum, expurgationem tom. I. Deliciarum Belgicarum. Eiusdem Poemata collecta \& edita à fratre Guilielmo Grotio= Item eisudem de lure Belli ac pacis donec expurgentur., pág. 487, Col. I.

En el Novissimum librorum prohibitorum et expurgandorum Index de 1640, se reproduce la "biografía" junto a otras obras, pero no el De lure (vid. págs. 513-514 et pág. 976). En cuanto al Index de 1667 de hecho reunía un index español que es el de 1640 y los romanos de Alejandre VII 
brirse su uso en otro género de literatura jurídica ${ }^{13}$. En definitiva, entre el Grocio herético de Solórzano y Pereyra y el Grocio "católico" de Ramos del Manzano, entre la descalificación y la conversión, no existía de hecho diferencia alguna. Una y otra posiciones no venían sino a reflejar una concepción del mundo y de la política ampliamente compartida en el interior de la Monarquía Católica que hacía de la "catolicidad» de la que había que dotar al mismo Grocio su indispensable clave de bóveda. Es precisamente sobre esta Weltanschauung, de fundameto catellano pero de dimensión universal sobre la que deseamos llamar la atención en nuestro artículo. Una Weltanschauung que tras sus inicios bajomediavales y altomodernos se consolidó en el periodo de las luchas confesionales que sacudieron la Europa Moderna y que se hallaba aún bien radicada en el centro de las concepciones políticas hispanas durante la segunda mitad del siglo XVII e incluso durante gran parte del siglo sucesivo ${ }^{14}$. Una Weltanschauung, en fin, que desde un punto de vista «interno" se caracterizaba por la ausencia de política propiamente dicha y por la presencia, en su lugar, de confesión y, en el ámbito "externo", por el desarrollo de un proyecto de dominación católico e hispano que, asentado sobre tales fundamentos, no podía abandonarse. Éste es el contexto en el que se recibía la obra de Grocio. Éste, esbozado, el objeto de nuestro trabajo.

2. "Son tan inseparables la paz y amor de Dios, que no gozará déste el que se hallare sin aquella". Así se expresaba el autor de una Relación que aparecía en 1637 en Málaga ${ }^{15}$. Pero, no se trataba solamente de «la interior paz del alma». El mismo autor nos lo indicaba:

y de Clemente VIII. Podemos recibir noticia así de que en el Index romano se encuentra, a diferencia del español, el De lure Belli.

13 Vid. LARREA, J.B. DE, Por el Real Fisco el doctor don Ivan Bautista de Larrea... Con el Duque de Arschot... Sobre la culpa que se le imputa en el trato sedicioso que para levantamiento de las Provincias fieles y obedientes de Flandes hizieron los Príncipes de Spinoy, Brabançon, Condes de Egmont, $y$ de Henin., fol. 18,67 in fine donde se cita el De iure Belii, lib. 2, Cap. 21. Para LARREA, Vid. recientemente, VOLPINI, P. "Las Allegationes Fiscales (1642-1645)", de Juan Bautista Larrea, Revista de Historia Moderna. Anales de la Universidad de Alicante, 15 (1996), págs. 465 y ss.

14 Vid. Fernandez Albaladejo, P., "Católicos antes que ciudadanos: gestación de una "Política española" en los comienzos de la Edad Moderna", en FORTEA PÉREZ, J.I. (Ed.), Imágenes de la diversidad. El mundo urbano en la corona de Castilla (s. XVI-XVIII), Cantabria, 1997, págs. 103 y ss.; PortiLlo, J.M., "Los límites de la Monarquía. Catecismo de Estado y constitución política de España a finales del siglo XVIII", Quaderni Fiorentini per la storia del pensiero giuridico moderno, 25 (1996), págs. 183 y ss.

15 Relación en que se declaran las trazas con que Francia ha pretendido inquietar los ánimos de los fidelisimos flamencos a que se rebelasen contra su rey y Señor natural, en OUEVEDO Y VILLEGAS, F. de, Obras Completas (Buendía, F. Ed.), T. I. Madrid, 1974, págs. 1.022-1.030. A pesar de que tanto Astrana Marin (Obras Completas. Madrid, 1932) como Buendia atribuyeron la obra a QUEVEDO - de hecho como en el momento de su publicación-, LópEz RUIz, A. que salvo los dos primeros fragmentos cuyo autor permanece desconocido, la obra es una copia incompleta de la Defensa de España contra las calumnias de Francia (1635) de Pellicer. Vid. López Ruiz, A., "Quevedo: un apócrifo más. La Relación de las trazas de Francia copia parcial de la defensa de 
"...y aunque es cierto que esto rigurosamente se entiende de la interior paz del alma, tambien lo es que sin la exterior se halla pocas veces" ${ }^{16}$.

San Isidoro y San Agustín venían en ayuda de nuestro anónimo autor para afirmar este carácter «exterior» de la paz, tal y como se nos presentaba. $Y$ es esta alusión patrística y, particularmente en nuestro caso, a San Agustín la que ahora nos interesa. Es manifestación, en efecto, de una concepción profunda que se mantiene y que es compartida pese a apariencias más superficiales. La obra del obispo de Hipona, es sabido, es profusamente recibida, citada y usada entre los autores de la Monarquia hispana. Ciertamente también en estos casos de referencia a la paz. Pero en estas posiciones, podríamos decir, más de «combate», ciertos escritos de San Agustín destinados esencialmente a responder a las pretensiones donatistas y, particularmente, sus bien conocidas epistolas tendrán una particular significación ${ }^{17}$. Especialmente, porque en estas cartas los autores hispanos podían encontrar la atribución a la Iglesia de una capacidad de forzar a los herejes y de reclamar a este efecto la colaboración de la autoridad secular. Y se trataba de una concepción que aparecía extremadamente coincidente con la percepción que de la Monarquía católica se tenía y de su posición en la escena europea ${ }^{18}$. De hecho, se podían encontrar las principales epistolas que ahora interesan en la Summa de Tomas de Aquino, precisamente en el lugar en el que se trataba de la admisibilidad del forzamiento respecto de los herejes ${ }^{19}$. Santo Tomás aña-

España de Pellicer», en Lopez RuIz, A., Quevedo, Andalucia y otras búsquedas. Almeria, 1991, págs. 11-24. $Y$ agradezco a Mercedes Sánchez esta información.

16 Relación... pág. 1.022.

17 Vid., San Agustin, epístola 93, en Obras Completas, VIII, Cartas (19\%. Madrid, 1986, págs. 602-58 y epistolas 173 y 185 en Obras Completas, $\mathrm{Xl}^{\mathrm{a}}$. Madrid, 1987. A propósito de la cuestión donatista y en general, MABkLS, R.A., "The Latin Fathers" en J.H. Burns (Ed.), The Cambridge History of Medieval Political Thought c. 350-c.1450. Cambridge, 1988, págs. 92-122. Voz, "Donatisme" en Dictionnaire de théologie Catholique (VACANT, A. y MANGEnot, E. Edts.), T. IV, II. París, 1911, págs. 1701-1728. Pero para una más adecuada inclusion de la cuestión del forzamiento de conciencias en el seno de los planteamientos teológicos de San Agustin, Markus, R.A., Saeculum: History and Society in the Theology of St. Agustine, Cambridge, 1970, págs. 33 y ss. Y, especialmente, ya para época moderna, GoLDIE, M., «The Theory of Religious Intolerance in Restoration England", en GreLL, O.P. ISRAEL, J. y TYACKE, N. (Edts.), From Persecution to Toleration. The Glorious Revolution and Religion in England, Oxford, 1991, págs. 330-368. Vid. asimismo San Agustin, Contra Epistolam Parmeniani et Contra Litteras Petiliani, sobre las que volveremos.

18 Otras lecturas -en otros contextos-podían realizarse de la cuestión donatista, de la posición de la autoridad secular -especialmente de Constantino- e incluso de las proposiciones agustinianas. Vid. para ello, TURCHETTI, M., Concordia o Tolleranza. François Bauduin (1520-1573) e $i$ "Moyenneurs". Milán, 1984, passim.

19 Summa Theologiae, lla 2ae, Quaestio 10, art. 8-11. En un sentido distinto del que aqui planteamos, MARAVALL, J.A., La oposición política bajo los Austrias. Barcelona, 1974, pág. 105. 
día, por su parte, toda una concepción, que también encontraba apoyo en ciertas proposiciones de San Agustín, que permitía una suerte de forzamiento "indirecto" sobre la conciencia en el momento de aceptar «la verdad", una acción que en principio debía de ser voluntaria. En efecto, si es el entendimiento el que nos dicta las acciones que deben de emprenderse y éste no puede ciertamente ser forzado, ello no impide que la voluntad pueda serlo de hecho con la intención de obligar al entendimiento a buscar la verdad, pues de la verdad se trata ${ }^{20}$. Además, la conciencia no era, no debía de ser sino "recta conciencia». Podemos imaginar sin excesiva dificultad las consecuencias más evidentes del diseño. En la Monarquía católica, podrá utilizarse con profusión tales presupuestos, bien que no fuese siempre necesario explicitar lo que era el fruto de una convicción profunda. Finalmente, la interpretación agustiniana del compelle intrare del Evangelio de Lucas $(14,23)$ sellaba la concepción ${ }^{21}$. Y era en este mismo cuadro en el que se insertaba a su vez toda una concepción de la utolerancia" que de una manera general venía a significar la posibilidad de soportar un mal -aquel de la admisión en determinadas circunstancias de herejespara evitar, si no había otra solución, un mal mayor ${ }^{22}$.

Se puede así comprender que el concepto mismo de paz resultase confesionalizado ${ }^{23}$. Se trataba de las consecuencias de la recepción que aca-

20 Summa, la 2ae, Quaestio 19. Vid. KILCuLlen, J., Sincerity and Truth. Essays on Arnauld, Bayle and Toleration. Oxford, 1988, esp.. II, págs. 54 et ss.

21 Vid., epístola $185,6.24$. epíst. $93,2.5$, epist. 173, 10. Vid. también, Sermo 112, dedicado a este pasaje del Evangelio de Lucas, in Obras Completas, X, Sermones (2), Madrid, 1983, págs. 795-804.

22 Summa, lla 2ae, Questio 10, art.11 con referencia al De Ordine de San Agustín. Juan RIQUELME en el prefacio de su ¿Para qué tiene el hombre razón?... publicado en Sevilla en 1687. nos señalaba a proposito de esta concepción que: "En el incauto concurso, que en puertos Catolicos enlaza el comercio, y tolèra la lglesia; aquel por las riquezas, esta por las animas; a cuyo ïn comio y bebiò nuestro Salvador con Publicanos, y pecadores; y tambien porque se elige la TOLERANCIA, quando no CABE EN LA PAZ EL CASTIGo, como enseña San Agustin, y el Pedro de los canonicos...", sin paginar. En este mismo sentido, Francisco Ramos DEL MANZANo establecía una bien significativa diferencia entre tolerar y permitir. "... y se ha no solo TOL.ERADO [en Francia] sino PERMITIDO con edictos Regios y nombre de libertad de consciencia, y de Religion Reformada, la heregia, y su publica profession, y disputas..." Vid. Ramos DEL Manzano, F., Respuesta. fol. 124 y 124 vto. En otros contextos, aun católicos (los Paises Bajos, por ejemplo) podia desarrollarse a partir de la misma base textual una concepción en principio menos instrumental de la tolerancia. Vid. para los casos de Lensaeus y Molanus, BIRELEY, R., The Counter-Reformation Prince. Antimachiavellism or Catholic Statecraft in Early Modern Europe. Chapell Hill, 1990, pág. 43. No obstante, parece necesario, en nuestra opinión, profundizar en las proposiciones de TURCHETT) (Concordia o Tolleranza, cit.) para evitar atribuciones de significados posteriores a las concepciones de la tolerancia de la época. Vid. también, del mismo autor, "Religious Concord and Political Tolerance in Sixteenth and Seventeenth-Century France", Sixteenth Century Journal, XXII, 1, (1991), pág.15 y ss.

23 En el mismo sentido, MÉCHOULAN, H., "La raison d'État dans la pensée espagnole au siècle d'Or, 1550-1650" en ZARKA, Ch-Y. (Ed.), Raison et déraison d'état. Théoriciens et théories de la raison d'État auX XVle et XVIle siècles. Paris, 1994, pág. 251. 
bamos de señalar. Se trataba, en fin, de los fundamentos de toda una Weltanschauung, en este sentido más inicial, más primario de confesión ${ }^{24}$. Unos fundamentos que contenían en si mismos un presupuesto primario de dominación. Sobre la religión, y sólo sobre ella, podía sustentarse la necesidad, pues de necesidad como veremos se tratará, de paz y de dominio ${ }^{25}$.

Pero aún hubieron de suceder algunas cosas en el seno de la Christianitas que serán de importancia decisiva para esta cosmovisión y para el diseño que de ella se derivaba. Lo serán, también, para hacer más significativas y más concretas tales afirmaciones de paz confesional, para calibrar posiciones y para identificar con mayor claridad los proyectos que se oponían a dicha paz confesional. En efecto, los "políticos" acabarán por aparecer en escena. Lo habían hecho ya desde finales del siglo XVI. Y sobre la base de la presencia constitutiva de la religión y de la ausencia de política (sobre la que volveremos) se reaccionaba frente a estas nuevas formas de política. Sobre todo, a partir de la década de los ochenta del Quinientos y con una atención especial sobre Francia, una Francia que supo encontrar una solución "política" a las guerras civil-confesionales ${ }^{26}$. La reacción se centraba en aquellas conductas a las cuales se atribuía la remoción integral de los fundamentos religiosos. Castilla, por su parte, no precisó en un primer momento de la importación de construcciones doctrinales europeas que perseguían, de forma general, el mismo fin ${ }^{27}$. En fin, en nuestro siglo XVII los "políticos" con su razón de estado ${ }^{28}$ se habían

24 Pardos, J.A., "Virtud complicada", en Continisio, Ch. y Mozzarelli, C. (EDTS.) Repubblica e Virtu. Pensiero Politico e Monarchia Cattolica fra XVI e XVII secolo. Milán, 1996, pág. 71-91.

${ }_{25}$ Vid. Straub, E., Pax et Imperium. Spaniens Kampf um seine Friedensordnung in Europa zwischen 1617 und 1635, Munich, 1980.

26 Fernández Albaladejo, P., “imperio de por sí: la reformulación del poder universal en la temprana Edad Moderna", en Fernández Albaladejo, P., Fragmentos de Monarquía. Trabajos de Historia politica. Madrid, 1992, págs. 168-184. ClaVERO, B., Razón de estado, razón de individuo, razón de historia. Madrid, 1991, Cap. I, págs. 15 y ss. Feanández Santamaría, J.A., Razón de estado y politica en el pensamiento político español del Barroco (1595-1640). Madrid, 1986

27 IÑuRritregui, J.M., La Gracia y la República. El lenguaje político de la teología católica y el Príncipe Cristiano de Pedro de Ribadeneyra. Madrid, 1998. Del mismo, “Antonio de Herrera y Tordesillas: Historia y Discurso político en Monarquía Católica" en ContINISIO, Ch.-MOzZARELLI, C. (Edts.), Repubblica e Virtù, págs. 121 y ss.

¿B "¿Cuál secta, cual herejia no se acomoda con el estadista, cuando no se ciñe y gobierna por la ley evangélica? Los perversos políticos la han hecho [a la razón de estado ] un dios sobre toda deidad, ley à todas superior», Francisco Quevedo, F. DE, Politica de Dios, Gobierno de Cristo. (CRosby, J.O. Ed.), II, Ch. VI, pág. 54. Madrid, 1966. La primera parte se publicó en Madrid en 1626 y la Segunda en 1655, también en Madrid. Vid. para las cuetiones relacionadas con la composición de la obra, JauRaLde, P.. Francisco de Quevedo (1580-1645). Madrid, 1998, págs. 400 y ss. Vid. para la cuestión de la razón de estado, Clavero, Razón de Estado, op. cit.; MECHOULAN, "Raison d'état" cit. Fernández-Santamaria, J.A., "Botero, Reason of State and Political Tacitism in the Spanish Baroque", en BALDIN।, E. (Ed.), Botero e la "Ragion di Stato". Atti del Convegno in Memoria di Luigi Firpo. Florencia, 1992, págs. 265-85. GonzÁlEZ, M., “Ética y Razón de Estado: de 
convertido en el verdadero enemigo. La paz no perdía su dimensión confesional más general pero se llenaba de un sentido concreto que se derivaba de esta identificación del enemigo. Francisco de Quevedo ya nos lo indicaba: hay "paz del mundo y una paz de Dios" ${ }^{29}$. A pesar de la significación más global de dicha afirmación, no resulta difícil en este contexto reconocer en los acuerdos políticos en materia de religión aquella paz de carácter puramente "mundano". Será contra dichos acuerdos que se pretenda hacer valer las referidas intenciones de dominación, incluso desde posiciones en principio menos sospechosas a estos efectos, como el mismo "neoestoicismo" quevediano. En efecto, la ataraxia, la apatheia que era su equivalente estoico, que constituían el fin último tanto de los planteamientos estoicos y neoestoicos, como de las corrientes escépticas, podían en efecto alcanzarse, y Lipsio no era una excepción, mediante la más firme imposición confesional ${ }^{30}$. La efectiva repercusión que hubo de tener Lipsio y en general la corriente estoica - con implicaciones también más generales pero igualmente vinculadas a la misma concepción del mundo ${ }^{31}$ - podía también entenderse. La matriz más general de referencia imponía así sus condiciones interpretativas ${ }^{32}$.

Quevedo a Saavedra Fajardo", en BALDINI, E. (Ed.), Aristotelismo politico e Ragion di Stato. Atti del Convegno internazionale di Torino, 11-13 tebbraio 1993. Florencia, 1995, págs. 227-48. GARCiA, C. y Álvarez de Morales, A., "Tacitismo, secularización y pensamiento político en España en el siglo XVII", en BALOINI, E. (Ed.), Aristotelismo, op. cit. págs. 383-393. Vid. nuestro trabajo, "Contra políticos atheistas. Razón católica y Monarquia hispánica en la segunda mitad del siglo xvII", en Prudenza civile, bene comune, guerra giusta. Percorsi della ragion di Stato tra Seicento e Settecento. Nápoles, 23-25 mai 1996 (en prensa).

29 Quevedo, F. DE., Política, op. cit.

30 Vid. Tuck, R., Philosophy and Government, 1572-1651. Cambridge, 1993, págs. 58 y ss. Del mismo, "Scepticism and toleration in seventeenth century", en MENDUS, S. (Edt.), Justifying Toleration. Conceptual and historical perspectives. Cambridge, 1988, págs. 21 y ss.

${ }^{31}$ La "récepción" de los principios estoicos -evidentemente cristianizados-y particularmente de Séneca puede vincularse con la reducción más propiamente castellana de política a moral y, en definitiva, a teología. Vid. en general, KRAYE, J, "Moral Philosophy" in SCHMITT, Ch.B. y Skinner, Q. (Edts.), The Cambridge History of Renaissance Philosophy. Cambridge, 1988, págs. 360-374. Y para la impronta de Sénaca el clásico, BLüHER, K.A., Seneca in Spanien. Untersuchungen zur geschichte der Seneca-Rezeption in Spanien vom 13. Jahrhundert bis 17 Jahrhundert. Múnich, 1969 (trad. española, Madrid, 1983), págs. 277 y ss.

${ }_{32}$ Marcos SAlmerón en su El Príncipe escondido. Meditaciones de la vida oculta de Christo, desde los doze hasta los treinta años, Madrid, 1648, recurría a Lipsio -y a Tácito- en un contexto de afirmación de la necesaria unidad confesional:

“... y que fuera muy útil se observara en la Naciones Católicas, para consevación de la fè pura, no dar lugar a que se intruduzgan [sic] nuevas sectas ni ceremonias contra la verdad de la Fè; pues como observò Justo Lipsio, la Religion verdadera, si se menosprecia, o cae de su autoridad, por admitirse otros errores, lleva tras si las Republicas a su perdicion... Y especialmente la heregia, cuya obstinacion mas facilmente se vence que se persuade...", Meditación XII, IV, pág. 163. 
De manera ciertamente ejemplar, ya nos señalaba Claudio Clemente en 1637 la necesaria coincidencia entre la oposición a los "estadistas" o "pseudopolíticos" y la "conservación y expansión» de la confesión católica ${ }^{33}$. Y no sorprende a estas alturas que los argumentos de oposición a los donatistas, con inclusión de la significativa epístola a Petiliano, se retomasen en este contexto de afirmación ${ }^{34}$. La defensa, en fin, de una cierta concepción de la Respublica Christiana, lo era también de mantenimiento de la propia Monarquía católica, de la Weltanschauung que en ella se encerraba. Se trataba, en efecto, de una cuestión existencial. Una vez más, Claudio Clemente, se encargaba de recordárnoslo al señalar que el Rey Católico se hallaba sometido, en lo que concierne a la religión, a :

«un género de contratos de los que en Theologia moral llaman Innominados; que es quando se da, ò se haze alguna cosa, para que el otro haga, ò de otra cosa en recompensa de lo hecho; ò recibido, la qual negociacion, quanto el Principe fuera mas prudente, $y$ mas cuydadoso, $y$ atento al bien de su Republica, tanto ha de procurar con mas instancia exercitarla con Dios, y esto sin que por esto incurra en nota de interesado» ${ }^{35}$.

La profunda convicción de que todos los conflictos en los que en estas décadas participa la Monarquía Católica -y particularmente la Guerra de los Treinta Años - se hallaban revestidos de ese carácter confesional también puede entenderse. «Religiosa es la Guerra que sustentamos, a Dios tenemos de nuestra parte" señalaba Palafox y Mendoza y lo repetía Francisco Enríquez en el marco más general de la búsqueda de las causas de la conservación y decadencia de las monarquías ${ }^{36}$. De manera aun más explicita, ya nos lo recordaba Gil de Velasco:

33 Clemente, C., El machiavellismo degollado. Por la christiana Sabiduria de España y de Austria. AlcalÁ, 1637. A pesar de la atribución de la obra por parte de ciertos autores (JOVER ZAMORA, J.M. 1635. Historia de una polémica y semblanza de una generación, Madrid, 1949) a Juan Eusebio Nieremberg, Fernandez-Santamaria (Razón de Estado, op. cit., pág. 38, n. 39) demuestra que Claudio Clemente no es seudónimo de NIEREMBERG, sino el nombre de su verdadero autor. La obra es traducción de la segunda edición en latín ya publicada en 1628, aunque el texto castellano intruduce adiciones $e$ incluso acontecimientos, datados, de 1637.

34 Clemente, C., Machiavellismo, cit., IV, pág. 59.

35 Ibidem, V, pág. 63-64.

36 Discursos espirituales del llustrissimo Señor Palafox y Mendoza recogidos por el R.P. Juan Antonio Velázquez, Madrid, 1641 , fol. $75 \mathrm{v}$. et $\mathrm{s}$. El texto es con seguridad posterior a 1634 y quizá inmediatamente posterior a la entrada oficial en guerra de la Monarquía hispana (1635). La obra se publicará en el vol. IV de Obras del autor, en la edicion realizada por Joseph de Palafox en 1664 (págs. 1 y ss.). Enriquez, F., Conservación de Monarquias, Religiosa y política. Madrid, 1648. que ya se hallaba concluido en 1647 (dedicatoria del autor de 22 de marzo de 1647). Sobre EnRIoUEZ, Vid. ARCO $r$ GARAY, R. DEL, La ldea del Imperio en la política y la literatura españolas, Madrid, 1944, págs. 252 y ss. Y sobre Palafox me aprovecho de la excelente Memoria de Licenciatura de Eva Botella Ordinas, Juan de Palafox y Mendoza y el pensamiento político de la Monarquía Católica. Madrid, UAM, 1998. 
«Por san Mateo dixo Christo nuestro Maestro y Señor: No penseis que vine yo al mundo a traer paz, no vine sino a traer cuchillo, por el qual se significa la guerra y la discordia... Paz segun se colige de la division de San Agustín... y Serafino Cumirano; es de dos maneras, una celestial y otra mundana, aquella justa y esta iniqua y mala..." ${ }^{37}$.

3. Tras todo este diseño se encontraba, en nuestra opinión, una inseparable conjunción entre el proyecto europeo sobre el que venimos insistiendo y la conformación constitucional castellana. Es de esta última cuestión de la que queremos ocuparnos en la páginas que siguen: presencia de religión y ausencia de política que constituian sus más íntimos fundamentos, y ello ya a partir de los momentos más iniciales de la época moderna ${ }^{38}$. Como ya vimos Palafox nos había advertido del carácter confesional de los conflictos contemporáneos. Al mismo tiempo, subrayaba esta relación entre fundamentos internos y posición "exterior»:

"Una Patria tenemos, y essa es Christo, no hay mas que una Nacion, y essa es Christianos" 39.

Una afirmación que, sin perder su referencia más general a una patria paradisi ${ }^{40}$, y que incluso en este sentido podía ser compartida por otras confesiones, encontraba una más concreta significación en nuestro contexto. Presencia de religión y ausencia de política, decíamos. De ello nos ocupamos. Repasemos al efecto otros testimonios. Son ciertamente necesarios para mejor comprensión del argumento.

Agustín de Castro, jesuita frecuentemente encargado de la redacción de censuras de obras del siglo XVII, leía en 1639 en un Colegio de la Compañía unos "proemiales políticos». Nos anunciaba un detenido examen de cuestiones vinculadas a la "policia", que es "facultad de gobernar comunidad compuesta de diferentes familias" y que si bien no constituye «propiamente scientia, porque no mira a razones universales sino hinc et nunc de la prudencia y se baria por el accidente" no es por ello menos noble pues, además de necesitar de todas las ciencias, constituye la mejor

37 GIL DE VELASCO, J.B., Católico y marcial modelo de prudentes y valerosos soldados, Triunfos de la unión católica y militar, Madrid, 1650, Cap.18, fol. 65. La obra ya se hallaba finalizada el 18 de octubre de 1644.

38 PARDOS, "Virtud complicada” cit. pág. 86.

39 Palafox, Discursos, op. cit.

40 Vid. para esta tradición, BLACK, A., Political Thought in Europe 1250-1450. Cambridge, 1992, págs. 52 y ss. Virou, M., For Love of the Country. An Essay on Patriotism and Nationalism. Oxford, 1995, pág. 20. 
parte de la "disciplina moral» ${ }^{41}$. Junto a esta consideración más general, el autor volvia a referirse a la policia al tratar de las formas de gobierno: monarquía, aristocracia y policía, un término éste último que el autor propone sustituir por democracia en vista de la posible confusión con aquella significación más global que ya referimos. Posteriormente, y de manera absolutamente tradicional, nuestro jesuita procederá a la ubicación de la soberanía en relación a cada forma de gobierno para acabar, como también era habitual, por afirmar la superioridad de la forma monárquica. Y se nos refería que el mejor modo de gobierno monárquico residía en la "mixtura" con la aristocracia y la democracia ${ }^{42}$. Pero aun habrá de descender a realidades más concretas. Agustín de Castro, con cita de Aristóteles, añadía así una distinción entre diversos géneros de "Reyno". De esta forma, «Reyno Regular es quando uno tiene toda la Potestad entera cabal y sin cohartacion ninguna para todo genero de negocios..." ${ }^{43}$. El ejemplo del pater familias ya contribuía a aclarar conceptos, un padre que es:

«...dueño en su cassa de manera que no ay en ella xenero de cossa ni resolucion que no penda de su arbitrio, sin que en alguna tenga subordinacion a otro, como Dueño absoluto en todas las disposiciones de los negocios que ocurren, assi el Rey regular es Dueño como Padre en su cassa en su Reyno..." ${ }^{44}$.

Y ya indicábamos que había llegado el momento de mayores precisiones. Es este género de "Reyno" "Propio el de Castilla y el mas conveniente de los cinco en que Aristoteles divide». La cuestión trascendía la simple afirmación monárquica. La reducción a "economía" en el sentido clásico del término había acabado por hacer desaparecer la política misma. No se trataba únicamente de la imposibilidad de introducir conceptos de la política que pudieran derivarse del humanismo cívico, de supuestos del republicanismo ${ }^{45}$. No se admitía tampoco concepciones de la política, que bien pudieran encontrarse en otros territorios aun monárquicos, vinculadas al mantenimiento de las “libertades" y a la participación en las cuestiones comunes. $\mathrm{Y}$, como podemos suponer, no se trataba de ignorancia o de falta

4 Castro, A. DE, Proemiales Políticos, Biblioteca Nacional de Madrid. Ms. 18721. En el margen puede leerse que el autor "en el año 1639 leyo en la Compa de Jesús". La cita en el fol. 412. Vid a propósito de esta obra, MARAVALL, J.A., La teoría española del estado en el siglo XVII, Madrid, 1944.

42 Castro, A. DE, Proemiales, Cit. fol. 424 v.

43 Ibidem, fol. 430 r.

44 Ibidem, fol $430 \mathrm{r}$.

45 Vid. por todos, Pocock, J.G.A., The Machiavellian Moment. Florentine Political Thought and the Atlantic Republican Traditon. Princeton, 1975, págs. 83 y ss. 
de información. El mismo Agustin de Castro nos decribia, incluso en el interior de Castilla, en el Señorío de Vizcaya, precisamente donde subsitían tales «libertades" ${ }^{46}$, la presencia de evidentes indicios republicanos. $Y$ en este mismo sentido, Palafox ya había advertido en 1631, a propósito de Cataluña que: «El modo de gobierno debajo de la mano del Rey y sombra de la Monarquía sabe algo a Republica...» ${ }^{47}$. Nos importa aquí menos la verdadera forma de gobierno del Principado que la percepción que se nos transmitía. Una percepción que en este caso Palafox realiza desde un punto de vista plenamente castellano. Entre la monarquía, tal y como Castro nos la presentaba, y la república no había lugar siquiera para una forma intermedia de monarquía fundada en "libertades", para una Monarquía Mixta si se quiere, tal y como podía hallarse en los territorios de la Corona de Aragón ${ }^{48}$ o en otros reinos europeos ${ }^{49}$. Lo hemos indicado, no se trataba de falta de información. El mismo Palafox ya se encargaba de evidenciarlo en unos Dictámenes espirituales, morales y políticos. El autor, en la parte dedicada a los "dictámenes morales" resumia las obligaciones del "hombre noble y christiano", según viva bajo monarquía o bajo república. Una obligación que era «...primero a Dios, segundo al Rey, tercero a su Padre, quarto a su patria, y quando es Republica, primero à su Patria, y luego à su Padre...» ${ }^{50}$.

46 Para una minuciosa reconstrucción de la historia constitucional del Pais Vasco, PORTILLO, J.M., Monarquía y Gobierno Provincial. Poder y constitución en las provincias vascas. Madrid, 1991, sobre todo, págs. 25 y ss. Y para las peculiaridades castellanas, Clavero, B. Mayorazgo. Propiedad feudal en Castilla, 1369-1836, Madrid, 1989 (1974). Del mismo, "Notas sobre el derecho territorial castellano, 1469-1445", Historia, Instituciones, Documentos, 3 (1976), págs. 143 y ss; Pardos, J.A., "Comunidad, Persona invisibilis", en Arqueologia do estado. Las Jornadas sobre formas de organizaçao e exercicio dos poderes na Europa do Sul. Séculos XIII-XVII, II, Lisbonne, 1988, págs. 113 y SS. Fernandez Albaladejo, P. y Pardos, J.A., "Castilla, Territorio sin Cortes (siglos XV-XVII)", Revista de las Cortes Generales, 15 (1988), págs. 113 y ss.

47 Palafox, J. DE, Diario del viaje de la Reina de Hungría. 1631. Edición de Aldea Vaquero, Q., en España y Europa. Correspondencia de Saavedra y Fajardo, T. I. Madrid, 1986, págs. 423 y ss. La cita en pág. 446.

${ }_{48}$ Vid. GIL PujoL, X., "Aragonese constitutionalism and Habsburg rule: the varying meanings of liberty", en KAGAN, R. y PARKER, G. (Edts.), Spain, Europe and the Atlantic world. Essays in honour of John H. Elliot. Cambridge, 1995, págs. 160 y ss. Del mismo, "Crown and Cortes in Early Modern Aragon: Reassessing Revisionisms", Parliaments, Estates and Representation, Vol. 13, 2 , (1993), págs. 109 y ss. Y para una perspectiva comparada, Fernández AlBaladejo, P., Fragmentos de Monarquía...,IIl, págs. 353-412.

49 Vid. BARUDIO, G., Absolutismus. Zerstörung der "libertären Verfassung". Studien zur "karolinischen Eingewalt», en Schweden zwischen 1680 und 1683. Wiesbaden, 1976. Del mismo, Gustav Adolf-der Grosse. Eine politische Biographie. Frankfurt a-Main, 1982, y con perpectiva más general, BARUDIO, G., Das Zeitalter des Absolutismus und der Aufklärung 1648-1779. Frankfurt a Main, 1981 (ed. española, Barcelona, 1986).

56 PALAFOX, J. DE, Dictámenes espirituales, morales y políticos, en Obras de... Vol. X, Madrid, 1762 Dictamen, XIX. Vid a propósito, JOVER, J.M., «Sobre los conceptos de Monarquía y nación en el pensamiento político español del siglo XVII", Cuadernos de Historia de España, XIII (1950), págs. 101 y ss. 
Pero habia más. Volviendo sobre estas referencias a la "patria», Palafox señalaba: "En las Monarquias, y Reynos, el buen vasallo no nace en su patria, sino en le corazon de su Rey, y a él se ha de ir todo su amor» 51. Falta asi de "patria» que reflejaba la más general ausencia de política, un vacío que hubo, por así decirlo, de rellenerse con la religión ${ }^{52}$. Hemos visto a Francisco Enríquez ofrecernos el año mismo de la firma de los tratados de Münster y Osnabruck ${ }^{53}$ una Conservación de Monarquías. Otras obras le acompañarán por estas mismas fechas ${ }^{54}$, pero nos interesa esta especialmente pues trata de la cuestión más esencial de la conservación de monarquías, como dijimos. Una conservación, nos señala el autor, a la vez religiosa y política ${ }^{55}$. Inútil repetir que las guerras presentes eran «propiamente de Dios porque son por causa de religión». El Rey Católico, la Casa de Austria pues la combinación entre religión y dinastía se había vuelto igualmente habitual ${ }^{56}$, constituyen el apoyo de una religión que es ubasa firme y estable de un Reyno". Los enemigos son también identificados entre herejes y esos "hombres meramente politicos" que se siven de la religión para acrecentar sus patrimonios, para mantener "el estado" y que "toman la religion por estado dela conservacion de sus monarquías". El Rey Católico, al contrario,

51 PaLAFOX, Dictámenes, cit. Dictamen, XX.

52 Vid. en este sentido, Clavero, B., Antidora. Antropologia católica de la economía moderna, Milán, 1991. Intentamos rastrear la subsistencia de tales fundamentos en nuestro trabajo, "El Sueño de Nabucodonosor", cit. Para su presencia en el primer constitucionalismo español, PORTILLO, J.M., "La historia del primer constitucionalismo español. Proyecto de investigación", Quaderni Fiorentini per la storia del pensiero giuridico moderno, 24 (1995), págs. 303 y ss.

53 La paz de Westfalia que, como es sabido, no fue firmada por la Monarquia Católica, tuvo una especial incidencia sobre la Weltanscahuung acerca de la que insistimos. La imposición de una Trennung entre las dos ramas de la Casa de Austria, el restablecimiento de las alibertades" en el Imperio y, sobre todo, el acuerdo supraconfesional se situaban en un plano absolutamente contrapuesto a esta visión del mundo.Para Westfalia, en el sentido señalado, BARudio, G., Der Teutsche Krieg 1618-1648. Frankfurt a Main, 1985. págs. 573 y ss. Para la subsitencia de tales fundamentos, SchINDLING, A., Die Anfänge des Immerwährenden Reichtags zu Regensburg. Ständvertretung und Staatskunst nach dem Westfälischen Frieden, Maguncia, 1991. Para la cuestión confesional, HECKEL, M., Deutschland im konfessionellen Zeitalter. Göttingen, 1983, págs. 181 y ss. Del mismo, "Die Krise der Religionsverfassung des Reiches und die Anfänge des Dreissigjährigen Krieges", en REPGEN, K.(Ed.), Krieg und Politik 1618-1648. Europäische Probleme und Perspektiven, Munich, 1988, págs. 107 y ss. Para la Trennung, DickMANN, F., Der Westfälische Frieden, Münster, 1985 (1959), págs. 260 y ss. Y para la posición de la Monarquía Católica, vid. nuestro trabajo, "Locuras de Europa», Espacio, Tiempo y Forma, Serie IV, t.7 (1994), págs. 425 y ss.

54 PONS DE CASTELVI, Gustavo Adolto de Suezia, vencedor y venzido en Alemania. Madrid, 1648. La dedicatoria del autor está fechada en 20 de diciembre de 1647. MiCHELI Y MARQUEZ, J., EI Fénix Católico Don Pelayo el Restaurador. Madrid, 1648 (la censura más antigua es de 20 de marzo de 1647).

55 EnRíuez, F., Conservación de Monarquías Religiosa y Política, cit.

56 Bajo este entendimiento confesional de la cuestión ya se trataba de la a...conservacion de la Monarchia de lesu Christo", lo que en gran medida dependía del hecho de que "... el sacro Imperio no salga de la Casa de Austria...", Conservación, cit. Parte I, Ch.. V, fol. 3v. 
"hace de la Monarquia el estado del aumento de la religion". Detrás quedaban las "malas artes» de la razón de estado. La afirmación de una concepción de pax et imperium a partir de estos mismos fundamentos religiosos no tardará en aparecer. Ciertamente podia irrumpir de manera bien explícita, pero se hallaba sobre todo presente de forma más esencial en el interior de todo un universo cultural que la mantenía. En efecto, San Agustín y su epístola a Bonifacio se encontraban alli para atestiguar su presencia. Una conservación que se convertía así en inseparable de la dominación. Pero se nos había prometido también una parte política, una conservación que se decía política. Y ciertamente, un parte que se titulaba "conservación de Monarquías en materia de policia» había. Mas también se nos advertía inicialmente que: «[la] Politica humana es mar tempestuoso a donde naufraga la conservacion de las Monarquias" y en definitiva la cuestión residía en no apartar "un punto" la vista del cielo pues era esta la regla propia de la "ciencia de gobernar Reinos, llamada comunmente politica". De nuevo nos encontrábamos en el mundo de la religión. Podía incluso habilitarse un espacio para la "prudencia", pero ésta tampoco acaba de salir del encuadramiento de virtudes más tradicional. Y se nos advertía que cyerra torpemente aquel que con reglillas de hombres agenos al cielo" pretende reducir a "método» el gobierno de las monarquías. Ninguna sorpresa, así, si encontramos entre estos últimos a los "políticos", y sus razones de estado, si Maquiavelo aparecía como su capitán o si se nos decía que entre unos y otros habían colocado la fortuna en lugar de la providencia. En estas coordenadas, sin que se percibiera en ello contradicción alguna, aprendíamos que en estas cuestiones de política al fin y al cabo la política no tenia sitio:

"La conservacion de la Monarquia Catolica depende, de que su Principe, no es tanto Monarca Politico, quanto Padre Economico" ${ }^{57}$.

En estas condiciones de ausencia de política, en una Monarquía así concebida, una relación “contractual» entre Rey y Reyno difícilmente cabía. Los «juegos» de dominios que en otros territorios permitían asentar una relación fundada en “libertades", aquí, en Castilla, no tenían sentido. Obligado el monarca por su "oficio" a la protección de la religión el juego de dominios se desplazaba hacia el cielo. El príncipe podía gozar de una suerte de dominio útil, pero era Dios quien gozaba del directo. El Regnum perdía así toda posibilidad de afirmación institucional. Todo era "economía". Todo acaba por reducirse a la cabeza del cuerpo político, al propio monarca. Así nos lo señalaba Andrés Mendo en su

57 EnRIQUez, F., Conservación, op. cit. 48r. 
Príncipe Perfecto ${ }^{58}$. El autor comenzaba por recordarnos la posición fundamental de la religión con sus consecuencias de conservación y de imposición ya conocidas ${ }^{59}$. No faltaba tampoco la combinación entre confesión y proyecto dinástico, que también conocemos ${ }^{60}$. Ciertamente, podía Mendo negar en principio una capacidad de disposición patrimonial del Príncipe sobre el Reyno; podía incluso introducir el pro lege et grege atribuido a "Alfonso el Emperador" o recurrir al símbolo del pelícano que, como es conocido expresaba en otros lugares la esencia del poder justo, para representar el poder del Príncipe ${ }^{61}$. Pero finalmente, es de un Príncipe Filósofo, de un Rey Sabio de quien se nos habla, pues el Príncipe es Idea de su reino, $y$ es de él de quien «..ha de manar al pueblo, quanto goza..." ${ }^{62}$. La importación platónica, tenía su sentido. Era ciertamente útil ${ }^{63}$. Mendo, en efecto, nos recordaba que «lo que hace el cielo con el resto del mundo, ha de hazer el Principe con sus Vasallos" ${ }^{64}$. Juan Eusebio Nieremberg precisaba aún el significado en una obra con título no menos significativo. En su Corona Virtuosa y Virtud Coronada y en unas Centurias de Dictámenes a ella incorporados no dudaba en señalarnos que se trataba, a su modo, de una cuestión de «libertad» ${ }^{65}$. Pero de aquel género de libertad que era directamente proporcional a la concepción del mundo que se compartía: "Género de libertad es servir al sabio, como de cautiverio mandar al necio" ${ }^{66}$. Que la virtud misma fuese coronada ya era significativo. Y ciertamente, "comunicación" entre Rey y súbditos existía, pero una vez más ese género de comunicación que cabía en el diseño más general, aquella fundada exclusivamente en «amor». Una caritas así que casaba a la perfección con el marco de refencia más esencial y menos político ${ }^{67}$.

58 Mendo, A., Príncipe Perfecto y ministros ajustados. Documentos políticos y morales. Salamanca, 1657. (primera ed. 1622).

59 lbidem, II, págs. 7-9.

60 Ibidem, cit.XIII, págs. 62 y ss, donde encontramos precisamente al “impio Machiavello", referencia que el autor toma de CLEMENTE, C. Machiavellismo, cit.

61 Ibidem, Docs. XI y XII.

62 Ibidem, Doc. XIX. pág. 94: “El rey Sabio es la firmeza mas estable de su Reyno. Es la publica salud, y remedio de los males. De la cabeza sabia de Apollo fingia la ciega gentilidad, que llovia la yerba Panacea, que era remedio de todos los achiaques, y salud de los pueblos...". Platón, se hallaba bien presente, (vid, entre otras, pág. 96).

63 Pardos, J.A., "Virtud complicad" op. cit., pág. 82.

64 MENdo, Príncipe perfecto..., op. cit., Doc. IX, pág. 45.

65 Juan Eusebio NiEREMBERG, Corona Virtuosa y Virtud Coronada, en que se proponen los frutos de la Virtud de un Príncipe, juntamente con los heroicos exemplos de Virtudes de los Emperadores de la Casa de Austria, Madrid, 1643. La censura más antigua es de 5 de julio de 1642. Las Centurias de Dictámenes, divididas en "Dictámenes Reales, Estoicos y Morales" ibid. págs. 313 y ss.

66 Nieremberg, J.E. Centurias de Dictámenes. Estoicos. Década IX, $\mathrm{n}^{9} 82$.

67 "No es oficio de descanso el del Rey; sino de solicitud y desvelo, pues es un suplemento de las necesidades humanas, ojos del ciego, manos del manco, pies del tullido, fortaleza del flaco, 
Que Tovar Valderrama expusiera en unas Instituciones Políticas, obra destinada a la instrucción del príncipe heredero y redactada bajo la presión de unas guerras que se entendía que subvertían el orden del mundo, que el fin último del orden político residía en la "contemplación», encontraba aquí su explicación y su sentido ${ }^{68}$.

En estas condiciones, "catolizar" a Grocio se convierte en una necesidad evidente, en nuestra opinión. El contexto de recepción lo imponía.

A pesar de la prohibición de 1732, el De lure Belli de nuestro autor conservó su influencia, al menos en medios reformadores, al parecer ${ }^{69}$. Pero se trataba ya de un debate diferente y las derivaciones que ciertos sectores podían obtener de las concepciones grocianas del derecho natural entonces podían parecer ciertamente peligrosas para el orden tradicional ${ }^{70}$.

amparo del huerfano, defensa de la vida, socorro del necesitado, alivio de todos, firmeza de la justicia y una caridad transcendental, por la cual le deven todos suma reverencia y entrañable amor, como a benefactor general, y sustituto de Dios", NIEREMBERG, Corona Virtuosa..., Cap. XVIII, pág. 154. Y vid. sobre estas cuestiones, Clavero, B., Antidora, op. cit.

68 Tovar ValderRama, D., Instituciones politicas al Serenissimo Señor Don Baltasar Carlos, (J.L. BermeJo, Ed.). Madrid, 1995. La obra apareció en 1645, aunque ya estaba compuesta para mayo de 1644.

69 Asi, Campomanes en una «l.ista de los libros principales, que tratan del derecho público y que deben adquirirse para una librería bien formada» (1753), en el capítulo dedicado al «Derecho Público Universal" insertaba a "Hugo Grocio". Vid. Llombart, V., Campomanes. Economista y político de Carlos III, Madrid, 1992, pág. 73.

70 Vid. TUCK, R., Philosophy and Government, cit. págs. 154-201. 